9. Кон И.С. Ребенок и общество. Учебное пособие для ВУЗов. М.: Академия, 2003.

10. Тер-Саркисянц А.Е. История и этнокультурные традиции. М.: Наука. Издательская фирма «Восточная литература», 1998.

11. Антонян Ю.Ю. Армянские мотивы в армянских родильных обрядах // Журнал Научная мысль Кавказа. 2001. № 1. C. $69-75$.

12. Бунятов Г. Рождение, смерть, погребальные обычаи и представление о загробной жизни у армян
Эриванской губернии // Этнографическое обозрение. 1896. № 1. С. 252-259.

Полевые материалы автора (ПМА):

ПМА, 2014-2015. г. Самара. Бабаян А.Х., 1957 г.р., урож. г. Баку; Бабаян Л.Р., 1981 г.р., урож. г. Баку; Агаджанян А.М., 1930 г.р., урож. Гадрутский р-он, с. Тамтур; Адамян Е.Л., 1938 г.р., урож. г. Сисиан, с. Уз; Айрапетян А.В., 1994 г.р., урож. г. Ереван, Агаджанова Я.Р., 1983 г.р., урож. г. Баку; Акопджанян Ж.Р., 1975 г.р., урож. г. Баку.

\title{
THE FIRST YEAR OF A CHILD'S LIFE IN AN ARMENIAN FAMILY (IN SAMARA)
}

(c) 2016

\section{L.A. Agadzanyan, senior lecturer of the Chair of Philosophy, History and Theory of World Culture} Samara State University of Social Sciences and Education, Samara (Russia)

Abstract. The theme of childhood is one of the most important and interesting in the Russian and foreign ethnography, because for a long time researchers have not given attention to this problem. In the middle of the XX century scientists emphasize the description of children's cycle ceremonies, public education. Today questions of birth and care of a child, his education in ethno-cultural and another cultural environment are in the forefront of the study of the peoples. Our investigation focuses on the first year of life of the children of Armenian ethnos living in the city of Samara. In this paper two sub-ethnic groups (Armenians from the Republic of Armenia, «Baku Armenians») of the Armenian community, that take different approaches to bringing up children are considered. This paper presents a consolidated material on the education, traditions and customs of the first year of life of the Armenian children. The article highlights the current issues of ethnography: pregnancy, childbirth and naming the baby, the postnatal period in the life of the child and the woman, nutrition, clothes, amulets, etc.

Thus, the study of this issue has shown that there are certain differences in some aspects of childhood culture between the two Armenian groups in Samara, albeit minor. «Baku Armenians» are more liable to other cultures and other ethnic influence, which manifests itself in the rites of baptism, fairy tales, cola-cabling, and you select a name for the baby.

Keywords: Armenians; family; childhood; naming ceremonies; birth rituals; child rearing; child birth; rituals; nutrition system; clothing; customs enforcement; charms; cultural environment; ethnography of childhood; Samara; ethnicity.

УДК $394+316.454 .2$

\section{АЗЕРБАЙДЖАНЦЫ В ПОЛИЭТНИЧНОЙ СРЕДЕ Г. САМАРЫ: ФАКТОРЫ ЭТНОКУЛЬТУРНОЙ ИДЕНТИЧНОСТИ}

(C) 2016

\author{
Ю.Н. Ширинских, учитель истории и обществознания
}

Общеобразовательная организащия «Потенщиал», Самара (Россия)

\begin{abstract}
Аннотаиия. Расширяющиеся культурные контакты между представителями различных этносов влияют на процесс самоидентификации их членов. Особо остро эта проблема стоит перед мигрантскими сообществами. Этническая общность существует постольку, поскольку имеются этноконсолидирующие факторы, и это обстоятельство делает изучение этничности особенно актуальным на сегодняшний день. В рамках данного исследования были выявлены факторы этнической идентичности азербайджанцев города Самары. Представители азербайджанской общины Самары строят свою идентичность на дифференцирующих признаках. Самым важным фактором этнической идентичности выступает язык. Азербайджанский язык наиболее функционален в общении с родственниками, друзьями и знакомыми, в семье. Интенсивность внутриэтнических контактов порождает потребность в его знании и стимулирует, таким образом, стабильное воспроизводство этнической группы. Знания языка передаются детям от родителей и старших родственников. Также факторами этнической идентичности азербайджанцев Самары выступают традиционная структура семьи, традиционная пища, праздники и траурные дни. Эти составляющие позволяют самарским азербайджанцам осознать свою национальную принадлежность и сохранить себя как сплоченную группу. Азербайджанцы Самары сами понимают важность названных факторов идентичности, сохранение которой является одной из основных задач национально-культурных объединений.

Ключевые слова: Самарская область, полиэтничная среда, мигрантские сообщества, самоидентификация, Самара, азербайджанцы, факторы этнокультурной идентичности, азербайджанский язык, традиционная пища, праздники, траурные дни, национально-культурные объединения.
\end{abstract}

Постановка проблемы в общем виде и ее связь с важными научными и практическими задачами. Самарскую область можно охарактеризовать как полиэтничный регион. Расширяющиеся культурные контакты между представителями различных этносов способствуют стиранию культурной самобытности народов, что, несомненно, отрицательно сказывается на культурной идентичности. Исходя из этого, становятся понятными стремления народов сохранить существующие отличия и особенности своей культуры. Особо остро эта проблема стоит перед мигрантскими сообществами, стремящимися сохранить культурную дистан- 
цию от принимающего сообщества. Факт того, что этническая общность существует постольку, поскольку имеются этноконсолидирующие факторы, делает изучение проблемы этничности особенно актуальной на сегодняшний день.

Анализ последних исследований и публикаций, в которых рассматривались аспекты этой проблемы и на которых обосновывается автор. Несмотря на попытки дать определение термину «этничность», в мировом научном сообществе нет общепринятой дефиниции данного феномена. Это связано, по мнению С. Чешко, с тем, что: «Все существующие теории оказываются неспособными выявить этническую «самость». Перед исследователями - явление, которое, безусловно, существует, но неизменно ускользает сквозь пальцы, несмотря на любые методологические ухищрения. Оно может проявляться повсюду, влияет на любые сферы жизни и деятельности человека и, в то же время, его нигде нет» [1, с. 39]. По мнению ряда исследователей, этничность является интеллектуальным конструктом, созданным людьми в ходе творческой социальной деятельности $[2$, с. $98 ; 3$, с. $14 ; 4$, с. 274]. Но есть иная точка зрения. Так, Ю.В. Бромлей [5, с. 176], Л.Н. Гумилев [6] определяют этничность как изначальную данность, свойственную человеку с момента его рождения. Согласно Ф. Барту, этнические границы во многом определяют жизнь людей, поэтому этническая группа сама принимает и устанавливает их [7]. Таким образом, принадлежность этносу определяется не только на основе врожденной этничности, но также путем осознанного самоопределения. На сегодняшний день существуют множество научных статей, посвященных исследованию факторов формирования идентичности различных этнических групп [8, с. 82-52]. Так, Е. Носенко считает, что «столпами» идентичности евреев можно считать общину, иудаизм, поддержку государства Израиль и Холокост [9, с. 111]. У греков Приазовья факторы идентичности другие: К. Кауринкоски выделяет национальную кухню, увлечение национальными песнями и танцами, спорт (греческая борьба куреш) [10, с. 99]. Таким образом, можно сделать вывод, что у различных этнических групп различен набор факторов этнической идентичности.

Формирование иелей статьи (постановка задания). Цель данного исследования - выявить факторы этнической идентичности у самарских азербайджанцев. Полевые исследования проводились автором с января 2015 по май 2015 в городе Самара. Велось наблюдение за поведением членов общины во время проведения праздничных мероприятий, траурных дат, собраний СООО «Лиги азербайджанцев Самарской области». Проводились полуформализованные интервью с членами азербайджанской общины.

Изложение основного материала исследования с полным обоснованием полученных научных результатов. Самарская область является одним из самых сложных регионов по этническому составу. По официальным оценкам, в Самарской области находится одна из крупнейших азербайджанских общин в России: 14093 человека (11789 проживают в городах и 2304 в селах) [11]. На момент последней переписи населения 2010 года численность азербайджанцев в Самаре достигла 4273 человека (2640/1633 муж/жен) [11]. Самара - крупный город с многонациональным составом населения. Городской образ жизни усложняет процесс воспроизведения народных традиций. Несмотря на это, традиционный образ жизни у самарских азербайджанцев сохраняется.

Одним из важнейших факторов этнической идентичности азербайджанцев Самары является азербайджанский язык. Как отмечает в своей работе С.С. Лазарян, «многие исследователи рассматривают язык как важнейший фактор этнической идентификации» [12, c. 81]. Языковой фактор влияет на формирование этнической идентичности и на внутриэтнические контакты азербайджанцев Самары. Интервьюированные - уроженцы азербайджанских городов и сел, воспитанные в азербайджанской культурно-языковой среде, умеют читать, писать и свободно говорить на родном языке. Все признают азербайджанский своим родным языком. В то же время уроженцы Азербайджана, выросшие в Советском Союзе, показали хорошее владение русским языком. Этому способствовало то, что он был языком межнационального общения.

Несомненно, в условиях мегаполиса межпоколенная трансляция лингвокультурного опыта усложняется естественным образом. Как показывает изучение языковой ситуации среди самарских азербайджанцев, полиэтничная городская среда Самары оказывает определенное влияние на воспроизводство языковой компетенции азербайджанского языка детьми, родившимися в моноэтничных азербайджанских семьях: они достаточно уверенно владеют устной речью, но не многие умеют писать на родном языке. Знания языка передаются детям от родителей и старших родственников, то есть основным агентом выступает семья и семейнородственная группа. Таким образом, община старается сохранить этнический язык, как один из главных объединяющих признаков этноса.

Дети от смешанных браков владеют азербайджанским на бытовом уровне, но не умеют писать поазербайджански. В то же время и в смешанных семьях самарских азербайджанцев создаются условия для усвоения детьми азербайджанского языка. Например, в семье К. Ровшана дочери владеют азербайджанским языком благодаря домашнему обучению и общению с родственниками отца-азербайджанца [13]. В подобных случаях успех усвоения детьми азербайджанского языка в значительной мере зависит от уровня языковых знаний родителей, от общения в родственном кругу, в первую очередь, с родственниками из Азербайджанской Республики.

В целом, азербайджанский язык наиболее функционален в общении с родственниками, друзьями и знакомыми, в семье. Интенсивность внутриэтнических контактов порождает потребность в знании его и стимулирует, таким образом, стабильное воспроизводство этнической группы.

Изучение самарскими азербайджанцами русского языка проходило постепенно, под влиянием внешних обстоятельств - при переезде, при обучении в русскоязычной школе или ВУЗе. Русский доминирует среди них на общественных мероприятиях, на работе, в общении с друзьями другой национальности. Так как круг связей азербайджанцев Самары наполнен в основном представителями своего этноса, можно сказать, что самарские азербайджанцы, будучи билингвами, отдают предпочтение в различных коммуникативных ситуациях родному языку.

Азербайджанский язык не просто показывает принадлежность к азербайджанскому этносу, но и служит воспитательным целям: «Человек, который начал раз- 
говаривать на азербайджанском, он по воспитанию отличается от человека, который начал разговаривать на русском. Чтобы сохранить свою идентичность, нужно начинать разговаривать на азербайджанском» [14].

В работе над сохранением языка принимают участие национально-культурные объединения. Одним из таких проектов можно считать воскресную школу, где преподавался азербайджанский язык. Проект проводился силами СООО «Лиги азербайджанцев Самарской области». Было найдено помещение, учебники привозились из Азербайджана, но проект оказался неудачным: потребности у детей в изучении языка не наблюдалась. Это связано с тем, что азербайджанский язык является достаточно функциональным в общении в семье. К тому же, присутствует постоянная связь (по телефону, скайпу) с родственниками, живущими в Азербайджане. Соответственно, страх потерять основу идентичности - родной язык - у самарских азербайджанцев отсутствует. Отсутствие этого страха и препятствует появлению воскресной школы азербайджанского языка. Другая проблема, связанная с открытием воскресной школы - отсутствие преподавателя с филологическим образованием, полученным в Азербайджане.

Еще одним фактором сохранения актуальности знаний азербайджанского языка в Самаре является ежемесячная информационно-аналитическая газета «Очаг». Статьи в газете печатаются как на русском (преимущественно), так и на родном азербайджанском языке.

Среди самарских азербайджанцев преобладают моноэтничные браки, что свидетельствует о стремлении этнической группы сохранить свою этническую культуру. Однако в вопросе семейно-брачных отношений азербайджанцы Самары не ограничены монокультурной (азербайджанской) средой, а открыты для контактов с другими этносами, имеют реальный опыт создания смешанных браков. Известны случаи браков с представителями русского, татарского [15] и чувашского [16] этносов. В то же время, такие браки не одобряются общиной, так как они менее прочны из-за бытовых неурядиц, являющихся следствием столкновения культур.

У молодежи и старшего поколения существуют различные представления о кандидатуре потенциальной невесты: если старшее поколение считает, что невесту нужно искать в Азербайджане [14], то молодежь стремиться найти супругу в Самаре, так как это упростит вопросы, связанные с трудоустройством, языковым барьером [15]. Стоит отметить, что если в прошлом при заключении брака мнение молодых учитывалось редко, то сегодня семья создается, как правило, из равноправных, самостоятельных, любящих друг друга молодых людей. Национально-культурные объединения проводят активную работу, направленную на сохранение семей.

В публичной жизни в Самаре азербайджанцы воспроизводят традиционные нормы общественной жизни, в которой женщины и дети не играют активной роли: при обсуждении важных вопросов на собраниях диаспоры женщины и дети участие не принимают. Поэтому в составе Самарской областной общественной организации «Лига азербайджанцев Самарской области» имеется женский клуб «Фемина», компенсирующий недостаточную публичную активность женщин. Любая азербайджанка может обратиться за помощью в этот клуб. Если семья находится на грани распада, то Лига старается урегулировать вопрос в семье и сохранить ее [14].

Таким образом, одним из значимых факторов идентичности является традиционная основа семьи. Патриархальность, представление о мужских и женских обязанностях, предпочтительность браков с представителями своего этноса являются основой отношений в семьях самарских азербайджанцев.

Пища - это тот элемент материальной культуры, в котором более других сохраняются традиционные черты, с ней более всего связаны представления народа о своей национальной специфике, и в то же время она легче и быстрее других поддается заимствованиям, вариациям, модификациям и новациям. Ее состав, способы приготовления повседневных, праздничных и обрядовых блюд, особенности приема пищи, застольный этикет - все это связано с этническим и социальным мировоззрением того или иного народа [17, с. 5-10]. По данным исследований этнологов и антропологов, традиционное питание составляет наиболее консервативную и специфическую часть культуры жизнеобеспечения различных народов. Это можно отнести как к народам, проживающим на своей исторической родине, так и к мигрантам, живущим в иноэтничном окружении.

Блюда и способы их приготовления относятся к числу наиболее стойких культурно-бытовых традиций. Так, мигранты, проживающие в инокультурной для них среде, относительно быстро меняют язык и одежду. Но традиции питания сохраняются с особой тщательностью. Необходимо отметить, что в сельской местности традиции питания сохраняются наиболее стойко. Однако, это не означает, что городское население нарушает свои пищевые привычки [18, с. 7-9].

Традиционная пища самарских азербайджанцев отличается большим разнообразием. Азербайджанские блюда преобладают в рационе питания, исключения могут составить лишь межнациональные браки, например, если супруга русская: «Кухня у нас в семье смешанная. <..> Она с удовольствием готовит азербайджанские блюда и блюда русской кухни. <..> Русская кухня не чужда мне с детства. Борщ, суп, пельмени, каши так же присутствуют в рационе» [13]. Bсе интервьюируемые осведомлены о специфике азербайджанской кухни. В числе азербайджанских блюд называют такие блюда, как несколько разновидностей плова, восточная родственница «голубцов»-долма, блюдо из баранины бозбаш. Упоминались такие блюда, как пахлава - одно из самых популярных кондитерских изделий, лакомство из дрожжевого теста шекербура, выпечка шора, холодный летний суп, сваренный из кефира и зелени - довга. Каждый интервьюируемый назвал не менее трех-четырех блюд традиционной азербайджанской кухни.

Рецепты приготовления блюд (наиболее часто упоминались довга, бозбаш, долма), несмотря на то, что интервьюируемые были мужчинами, указали все респонденты. В моноэтничной азербайджанской семье национальные блюда преобладают в рационе, однако, также присутствуют блюда, не типичные для исторической родины азербайджанцев, например борщ, щи [19]. В смешанных браках рацион питания представлен как блюдами азербайджанской кухни, так и блюдами дру- 
гих народов. Азербайджанская кухня нравится интервьюированным не просто вкусовыми качествами, но и воспринимается как воспоминание о родителях (о бабушке, маме) и о детстве («вкус детства»). Таким образом, в условиях иноэтничного окружения рацион питания подвергся трансформации, но основной стержень традиционной кухни сохранился. Можно сказать, что традиционная пища у самарских азербайджанцев вписана в контекст их повседневности и является неотъемлемой частью рациона, что символизирует связь с домом и родственным кругом.

Существует мнение, что любое проявление культуры всегда связано с этносом. Это можно отнести и к спорту. Сегодня теория этноспорта внесла свои коррективы в понимание этого социокультурного явления [20, с. 11]. С давних пор одними из любимых занятий азербайджанцев были нарды и шахматы. Популярны эти виды спорта и у самарских азербайджанцев. На базе национально-культурных объединений проводятся соревнования по нардам [21] и шахматам [22]. В соревнованиях принимают активное участие члены азербайджанской общины разных возрастных групп.

Одним из важных элементов традиционной культуры является одежда. Она отражает историческое и социокультурное развитие народа. На современном этапе роль национального костюма у азербайджанцев изменилась. Он потерял утилитарное назначение и перешел из материально-вещевой в духовно-символическую. Азербайджанский костюм, как атрибут национальной культуры, используется на праздничных мероприятиях во время выступлений на сцене, для презентации своей культуры на различных мероприятиях. В полиэтничном пространстве Самары азербайджанский костюм является визуально-привлекательным и ярким индикатором национальной культуры. Таким образом, национальный костюм символизирует единение самарских азербайджанцев, подчеркивает их сопричастность со своим народом.

Ярким примером сохранения традиций у самарских азербайджанцев являются праздничные мероприятия и памятные дни, проводимые членами общины. Наряду с религиозными интервьюируемые отмечают также государственные (28 мая - День Республики и др.) и светские календарные праздники (8 марта, Новый год и др.). Особо почитаются Навруз, Курбан Байрам. Светские и государственные праздники в семьях празднуются редко, и в основном, проходит в форме застолья. Например, День солидарности азербайджанцев мира совпадает с Новым годом (31 декабря).

Большинство мероприятий являются формами досугового поведения части азербайджанцев города либо публичным концертом и связаны с общественным объединением. Одним из самых активных общественных объединений является СООО «Лига азербайджанцев Самарской области», созданная 28 мая 2003 года. С момента создания «Лига азербайджанцев Самарской области» участвует в таких межнациональных фестивалях, как «Венок дружбы», «Межнациональный Навруз» и др. При проведении праздников используются следующие формы самопрезентации этнической культуры: танцы, исполнение песен, поэзия, дегустация блюд национальной кухни.

Одним из самых почитаемых праздников является Навруз. Этот праздник отмечается как в семейном кругу с родными и друзьями, так и в рамках городского мероприятия. Концерт проводится совместными силами СООО таджикистанцев «Пайванд-Единство», СОО «Национального узбекского культурного центра «Алишер Навои», СООО «Узбекской общины», СООО «Лиги азербайджанцев Самарской области», и других представителей национально-культурных объединений Дома Дружбы Народов [23]. Таким образом, праздничные мероприятия демонстрируют своеобразие азербайджанской культуры, связывают воедино символы идентичности: язык, религию, костюм.

Особо стоит отметить траурные события в истории азербайджанского народа, такие как День памяти жертв «черного января» 1990 г. (20 января) и День памяти жертв Ходжалинской трагедии 1992 (26 февраля). 20 января 1990 г. произошло подавление политической оппозиции подразделениями Советской Армии в столице Азербайджанской ССР - городе Баку, закончившийся гибелью более сотни мирных жителей, в основном азербайджанцев. 26 февраля 1992 году произошло массовое убийство жителей азербайджанского города Ходжалы, которое в ряде источников характеризуется как самое крупное и жестокое кровопролитие за время Карабахской войны. Проведение траурных дней позволяет самарским азербайджанцам укрепить историческую память о родине, сочувствовать и сопереживать событиям, относящимся к своей родине. Таким образом, роль траурных событий велика в формировании исторического сознания и чувства принадлежности к своему народу.

Приобщение участников общины к этническим традициям проходит посредством обучения народным танцам. В конце 2008 года в Самаре сформировался танцевальный коллектив «Хаял». Занятия и репетиции коллектива проводятся регулярно в актовом зале ГКУ СО «Дом дружбы народов». В состав коллектива входят около 50 человек. Коллектив делится на три группы - младшую, группу среднего возраста, старшую группу. Ставятся такие танцы, как «Сары гялин», «Шалахо», «Узундере» и «Танец с нагарой» [24, с. 1]. Кроме азербайджанцев, занятия посещают представители других национальностей, что свидетельствует о тесном контакте различных культур. Танцевальный коллектив «Хаял» является активным участником мероприятий различных уровней.

Bыводы исследования и перспективы дальнейших изысканий данного направления. На основании проведенного исследования можно сделать следующие выводы. Представители азербайджанской общины Самары строят свою идентичность на дифференцирующих признаках. Самым важным фактором этнической идентичности выступает язык. Поэтому община стремится сохранить его. Также факторами этнической идентичности азербайджанцев Самары выступают традиционная структура семьи, традиционная пища, праздники и траурные дни. Эти составляющие позволяют самарским азербайджанцам осознать свою национальную принадлежность и сохранить себя как сплоченную группу. Азербайджанцы Самары сами понимают важность названных факторов идентичности, сохранение которой является одной из основных задач национально-культурных объединений.

\section{СПИСОК ЛИТЕРАТУРЫ:}

1. Чешко С.В. Человек и этничность // Этнографическое обозрение. 1994. № 6. С. 35-49. 
2. Тишков В.А. Реквием по этносу: Исследования по социально-культурной антропологии. М.: Наука, $2003.544 \mathrm{c}$.

3. Александренков Э.Г. «Этническое самосознание» или «этническая идентичность»? // Этнографическое обозрение. 1996. № 3. С. 13-22.

4. Брубейкер Р. Этничность без групп / пер. с англ. И.Борисовой. М.: Изд. дом Высшей школы экономики, 2012. 408 c.

5. Бромлей Ю.В. Очерки теории этноса. М.: Наука, $1983.418 \mathrm{c}$.

6. Гумилев Л.Н. Этносфера: История людей и История природы. М.: Экопрос, 1993. 544 с.

7. Барт Ф. Этнические группы и социальные границы. Социальная организация культурных различий: Сборник статей / под ред. Ф. Барта; пер. с англ. И. Пильщикова. М.: Новое издательство, 2006. 200 с.

8. Горохов С., Лийметс А. Об идентичности национальных групп жителей Эстонии (ситуация в Нарве) // Диаспоры, 2003. № 4. С. 8-52.

9. Носенко Е. Факторы формирования еврейской идентичности у потомков смешанных браков // Диаспоры. 2000. № 3. С. 11.

10. Кауринкоски К. Греки Приазовья: особенности этнокультурной идентичности // Диаспоры. 2002. № 1. C. 99.

11. Всероссийская перепись населения 2010 г. // Демоскоп Weekly. URL: http://demoscope.ru/weekly/ssp/ rus etn 10.php?reg=55.

12. Лазарян С.С. Структура и критерии формирования этнической идентичности личности // Человек и образование. 2008. № 2. С. 81-83.

13. ПМА 3, 2015 г., г. Самара: интервью с Р. Кулиевым, 1965 г.р., урож. г. Менгечаур Евлахского района Азербайджанской ССР.

\section{AZERBAIJANIS IN THE MULTIETHNIC ENVIRONMENT OF SAMARA: FACTORS OF ETHNOCULTURAL IDENTITY}

(C) 2016

Yu.N. Shirinskikh, teacher of history and social science

Educational organization «Potential», Samara (Russia) кавказья. М., 1996. 163 с.
14. ПМА 1, 2015 г., г. Самара: интервью с Ш.М. Керимовым, 1967 г.p., урож. г. Зангилан Зангиланского района Азербайджанской ССР.

15. ПМА 2, 2015 г., г. Самара: интервью с С. Бабаевым, 1988 г.р., урож. г. Баку Азербайджанской ССР.

16. ПМА 5, 2015 г., г. Самара: интервью с И. Мамедовым, 1984 г.р., урож. города Гянджа Азербайджанской ССР.

17. Традиционная пища как выражение этнического самосознания. М.: Наука, 2001. 293 с.

18. Григулевич Н.И. Этническая экология питания. Традиционная пища русских старожилов и народов За-

19. ПМА 4, 2015 г., г. Самара: интервью с Ф. Гусейновым, 1970 г.р., урож. г. Лерик Лерикского района Азербайджанской ССР.

20. Кыласов А. Этноспорт. Конец эпохи вырождения. М.: Территория будущего, 2013. 144 с.

21. Турнир ЛАСО: доживем до следующей субботы // [Блог ежемесячной газеты Лиги азербайджанцев Самарской области «Очаг»]. URL: https://ochagsamara. wordpress.com/2015/02/14/турнир-ласо-доживем-доследующей-субб.

22. Как давно мы не играли в шахматы... // [Блог ежемесячной газеты Лиги азербайджанцев Самарской области «Очаг»]. URL: https://ochagsamara.wordpress. com/2015/03/25/как-давно-мы-не-играли-в-шахматы.

23. Нариманов Р. Новруз 2014: праздник удался. Самарские татары / информационный ресурс URL: http://samtatnews.ru.

24. Сулейманов X. Танцуем - значит существуем... // Очаг. 2012. № 10. (93), октябрь. С. 1.

\footnotetext{
Abstract. Increased cultural contacts between representatives of different ethnic groups affect the process of selfidentification of their members. Especially it concerns migrant communities. Examination of the problem of ethnicity is especially important due to the fact that the ethnic community exists until there are ethnoconsolidating factors. Within the framework of this research factors of Samara's Azerbaijanis ethnic identity were revealed. Representatives of the Azerbaijani community of Samara base their own identity on differential features. Language is the most important factor of ethnic identity. The Azerbaijani language is the most functional in communication with relatives, friends and acquaintances, in the family. The intensity of intra-ethnic contacts leads to the necessity of language skills and stimulates stable reproduction of the ethnic group. Language skills are transmitted to children from their parents and older relatives. Traditional family structure, traditional food, holidays and mourning days are also factors of ethnic identity of Samara's Azerbaijanis. These components allow Samara Azerbaijanis to realize their national identity and to preserve themselves as a cohesive group. Azerbaijanis of Samara realize the importance of these identity factors whose preservation is one of the main aims of national and cultural associations.

Keywords: Samara Region, multi-ethnic environment, migrant communities, self-identification, Samara, Azerbaijanis, factors of ethno cultural identity, Azerbaijani language, traditional food, holidays, mourning days, national and cultural associations.
} 